\title{
COMUNICAÇÃO E VIOLÊNCIA URBANA: TRÊS TEXTOS EM QUE A INTERTEXTUALIDADE CONSTROI O DISCURSO
}

\section{COMMUNICATION AND URBAN VIOLENCE: THREE TEXTS WHERE THE INTERTEXTUALITY IS THAT BUILDS THE SPEECH}

\author{
Marta Cardoso de Andrade ${ }^{1}$ \\ Hélder Uzêda Castro ${ }^{2}$
}

\begin{abstract}
RESUMO
Este artigo visa apresentar uma reflexão sobre a intertextualidade como um princípio constitutivo que trata o texto como uma comunhão de discursos, bem como estudar como esses discursos são construídos para imputar sentido às produções textuais. Para tanto, foram selecionados três textos, oriundos do trabalho da Comunicação Social: uma charge, uma tirinha e um anúncio publicitário. Foram utilizados as seguintes teorias como base para as análises empreendidas: a Análise do Discurso (AD), de linha francesa; e a Linguística Textual; sendo que a primeira constitui-se igualmente uma metodologia que direciona os estudos focados em discursos.
\end{abstract}

Palavras-chave: Violência urbana. Comunicação. Discurso. Intertextualidade. ethos.

\begin{abstract}
This article presents a reflection on intertextuality as a constitutive principle that treats the text as a fellowship of discourse and study how these discourses are constructed to impute meaning to textual productions. Three texts originating from the Communication were selected: a cartoon, one strip and an advertisement. The following theories as the basis for the current analysis were used: Discourse Analysis (DA), the French line; and Textual Linguistics, the first of which also constitutes a methodology that directs the making of studies focused on speeches.
\end{abstract}

Keywords: Urban violence. Communication. Discourse. Intertextuality. ethos.

1 Doutora e Mestra em Letras, com corpus de pesquisa em Comunicação Organizacional, pela Universidade Federal da Bahia (UFBA). Professora Adjunta da Universidade Salvador (UNIFACS), da Falculdade Ruy Barbosa e da Faculdade Área1. E-mail: marta.andrade@unifacs.br.

2 Mestre em Administração pela Universidade Salvador (UNIFACS). E-mail: helderuzeda@gmail.com 


\section{CONSIDERAÇÕES INICIAIS}

Cidades cada vez maiores, chegando às megalópoles com crescentes populações e com renda concentrada na mão de poucos; consumo como o "grande caminho" para a felicidade, resultando na valorização do "ter" em detrimento do "ser"; mulher cada vez mais vista como objeto; proliferação das drogas; acesso às armas de fogo e banalização da vida humana são fatores que muitos apontam como grandes geradores da violência urbana.

Para Luciana Phebo e Anna Tereza Moura (2005, p. 189),

A violência urbana configura-se como um dos principais problemas sociais da atualidade. No Brasil, em especial nos grandes centros, a violência pode ser identificada como a maior preocupação apontada pela sociedade e vem sendo alvo de inúmeros debates no âmbito público e privado. É um tema que abarca fenômenos das esferas social, política e econômica, repercutindo diretamente na qualidade de vida da população.

Essas mesmas teóricas alertam que há diversas formas desse tipo de violência. Salientam que esta acontece no meio urbano e possuem como ponto em comum a estrutura das grandes cidades, a qual fomenta por si só um distanciamento entre os seres humanos e uma proriferação da sensação de impunidade e medo coletivo.

A massa de construções faz perder a simples perspectiva do horizonte, da natureza, inclusive da natureza humana. A isso se pode adicionar as formas de viver em geral, cada vez mais empilhadas e apertadas. A aglomeração populacional é inversamente proporcional à possibilidade de contatos afetivos mais profundos. O anonimato e a sensação de "não pertencer" são duas condições constantes nas cidades grandes. O tempo é escasso tanto para os outros como para si mesmo. Há pressa e uma sensação de falta de lugar e de oportunidades para todos, imperando a competição e o imediatismo. Prevalecem angústias e vazios, os quais se busca preencher e apaziguar através de estímulos sonoros e visuais e através de um consumo desenfreado e inconseqüente [sic] (PHEBO; MOURA, 2005, p. 2).

Milton Santos (1988), ainda no século passado, já advogava que havia um ruído enorme, ambien- tal e nas comunicações de modo geral, com o qual para o ser humano era difícil escutar e escutar-se.

Todos esses fatores contribuem para estados emocionais e comportamentais que são meios propícios à produção de várias formas de violência.

Pensando nisso, foi realizada uma pesquisa a qual estuda três textos produzidos pela Comunicação que alertam sobre a violência urbana. Para tanto, usou-se o princípio da intertextualidade discursiva e textual, não entre os textos selecionados e sim entre esses e outros verbalizados e presentes na sociedade. Dessa forma, este documento versa acerca da análise dessas três produções, a partir das vozes de outros textos presentes na construção discursiva dos selecionados para esta investigação.

Para se fazer a referida análise foram utilizadas as seguintes teorias: a Análise do Discurso (AD), de linha francesa, a qual disseca o discurso a partir dos elementos linguísticos que o compõe e dos elementos constituintes do co-texto; e a Linguística Textual, que é considerada como uma "Disciplina auxiliar da análise do discurso [...]" (MAINGUENEAU; CHARAUDEAU, 2004, p. 307) e que pesquisa a intertextualidade como recurso construtor do sentido dos textos.

O objetivo deste trabalho é entender como se constroi um texto a partir do já verbalizado em outros textos presentes na sociedade visando-se alertar sobre a violência urbana, bem como busca-se a compreensão de como outros discursos podem auxiliar na produção de um discurso impactante, eficaz e eficiente no combate a tal violência.

Assim, como foi mencionado, serão investigadas três produções textuais, um anúncio publicitário, uma charge e uma tirinha, oriundas da atividade da Comunicação Social, cada uma dessas abordando um tipo de violência vivenciada nos centros urbanos.

\section{CONCEITOS BASILARES}

O fenômeno denominado de Violência Urbana, além de ter uma presença constante e indesejada na sociedade contemporânea, ainda tem "proliferação [...] inevitável e a sua evolução tende a ser cada vez maior", conforme afirma Susana Barata (2008, p. 6).

Cabe, então, definir o que seria característico desse tipo de violência. Esta 
[...] consiste em um tipo de violação da lei penal. Consiste na prática de crimes diversos contra pessoas (assassinatos, roubos e sequestros), e contra o patrimônio público, influenciando de forma negativa o convívio entre as pessoas e a qualidade de vida. Esse tipo de violência manifesta-se particularmente nas grandes cidades. Um dos principais fatores que gera a violência urbana é o crescimento acelerado e desordenado das cidades. Como consequência [sic] surgem graves problemas sociais como fome, miséria, desemprego e marginalização, que associados à ineficiência das políticas de segurança pública contribuem para o aumento dos atos de violência. (CABRAL; FRAZÃO, 2014, s.p.).

Para Alina Esteves (1999, p. 29) a violência urbana teria sua origem em

[...] o número de habitantes de uma urbe influencia a vida social, na medida em que quanto maior o número de pessoas, maior a frequência de contactos [sic] entre desconhecidos e maiores oportunidades se geram para a prática de furtos, roubos e agressões. [...] nível das diferenças sociais, económicas [sic], étnicas e etárias entre as pessoas residentes, ou ao nível das atividades económicas [sic] desenvolvidas, é um elemento potenciador de actos [sic] criminosos.

Apesar de ser considerada, em maioria, centrada nas grandes cidades, Caio César Gomes (2014, s.p.) destaca que

[...] engana-se quem acredita que o fenômeno da violência urbana está restrito aos grandes centros. Esse problema pode ser observado também em pequenos centros urbanos, em todo o país, onde recentemente as manchetes dos jornais mostram um aumento no número de assaltos, homicídios e outros atos de violência, o que deixa as populações locais apreensivas. Isso comprova que a violência tem tomado proporções gigantescas e atualmente é configurada como um "morbus social" [...]

Esse mesmo estudioso cataloga possíveis formas desse tipo de violência

[...] se personifica de diversas formas e pode ser caracterizada igualmente: violência contra a mulher, violência moral, violência sexual, violência contra a criança e o idoso, entre outras. Cabe salientar que essas diversas formas de violência podem ser observadas em vários espaços, sendo o meio urbano o mais propicio para o desencadear destes atos. Destarte, todo esse conjunto de violências pode ser inserido no âmbito da violência urbana. [...] é determinada por valores culturais, sociais, econômicos, políticos e morais de uma sociedade. De forma mais específica, pode-se associar alguns problemas e práticas que contribuem como o crescimento da violência urbana: desestrutura familiar, desemprego, tráfico de drogas, discussões banais, entre outros. Hoje, a violência urbana não é uma preocupação exclusivamente brasileira, mas sim uma questão que preocupa tanto os países em desenvolvimento como os desenvolvidos. (GOMES, 2014, s.p.).

Como cabe aos profissionais da área de Comunicação Social a produção de textos que espelhem as preocupações circulantes na sociedade em um dado momento, a temática da violência urbana, assunto "efervescente" na atualidade, termina sendo uma constante nas redações jornalística e até na publicidade.

Para efeitos deste trabalho, foram escolhidos um exemplar de três gêneros textuais ${ }^{3}$ : uma charge, uma tirinha e um anúncio publicitário, os quais se debruçam sobre o tipo de violência em questão. Salientando-se que se deve delimitar o que vem a ser cada um desses.

Dessa forma, entende-se por charge o gênero que compõe a família das $\mathrm{HQs}^{4}$, geralmente exposta em apenas um quadro, e é expresso a partir de uma "[...] ilustração ou desenho humorístico, com ou sem legenda, veiculado pela imprensa, que tem por finalidade satirizar e criticar algum acontecimento do momento" (COSTA, 2009, p. 60), sendo, portanto, um texto opinativo. Segundo Costa (2009, p. 60), esse "Focaliza, por meio de caricatura gráfica, com bastante humor, uma ou mais personagens envolvidas no fato político-social que lhe serve de tema [...]".

Enquanto que a tirinha caracteriza-se por ser um "segmento ou fragmento de HQs, geralmente com três ou quatro quadros, apresenta um texto sincrético que alia o verbal e o visual no mesmo enun-

\footnotetext{
3 Para Marcuschi (2008), "Gênero textual refere os textos materializados em situações comunicativas recorrentes. [...] são os textos que encontramos em nossa vida diária e que apresentam padrões sociocomunicativos característicos por composições funcionais, objetivos enunciativos e estilos concretamente realizados na interação de forças históricas, sociais, institucionais e técnicas" (p. 155). Assim, entendido como "[...] uma forma de realizar linguisticamente objetivos específicos em situações sociais particulares" (p. 154).

4 HQs é a sigla de histórias em quadrinhos.
} 
ciado e sob a mesma enunciação" (COSTA, 2009, p. 191). Igualmente é um texto opinativo, circulante em jornais ou revistas, o qual é publicado na seção ou caderno destinado ao entretenimento do leitor. Contudo, pode também ter cunho crítico e reflexivo sobre uma determinada questão tratada socialmente na atualidade.

Por fim, o anúncio publicitário ou simplesmente propaganda é destinada, predominantemente, à venda de "[...] produtos através de mensagens [...] que procuram convencer para conseguir consumidores. [Estas] são curtas, breves, diretas e positivas, com predomínio da forma imperativa [...], presente $[\ldots]$, um enunciado repetido à exaustão" (COSTA, 2009, p. 171). Mas esse gênero ainda possui uma outra peculiaridade, destacada por Costa (2009, p. 171):

\begin{abstract}
Aliado a essa estratégia discursiva verbal, o texto publicitário compõe-se também de linguagem não verbal, em que o formato do suporte, as imagens, ilustrações e animações são de grande importância na construção de um discurso que explora os desejos de consumo da sociedade moderna. [...] É um gênero textual essencialmente multissemiótico, em que os argumentos de venda, embora pareçam lógicos, caracterizam-se por apelos totalmente emocionais e pelo uso de padrões sociais, estéticos, [sic] etc. estereotipados.
\end{abstract}

Ao mencionar o vocábulo "discurso", cabe afirmar que cada um desses três gêneros terminam por construir um discurso, no caso deste artigo, o de alerta contra a violência urbana.

Cabe então entender o que vem a ser um discurso. Sabe-se que o conceito deste adentra o campo da Comunicação pela Análise do Discurso (AD), de linha francesa. Assim, antes entender seu conceito convém compreender em que consiste a AD. Para efeito de demarcação da gênese da teoria, pode-se, então, afirmar que essa

[...] é a herdeira das três regiões de conhecimento - Psicanálise, Lingüística [sic], Marxismo - não o é de modo servil e trabalha uma noção - a de discurso - que não se reduz ao objeto da Lingüística [sic], nem se deixa absorver pela Teoria Marxista e tampouco corresponde ao que teoriza a Psicanálise. Interroga a Lingüística [sic] pela historicidade que ela deixa de lado, questiona o Materialismo perguntando pelo simbólico e se demarca da Psicanálise pelo modo como, considerando a histori- cidade, trabalha a ideologia como materialmente relacionada ao inconsciente sem ser absorvida por ele. (ORLANDI, 2002, p. 20).

Em relação ao discurso, Eni Orlandi (2002, p. 15) afirma que "[...] a palavra discurso, etimologicamente, tem em si a idéia [sic] de curso, de percurso, de correr por, de movimento. O discurso é assim a palavra em movimento, prática de linguagem [...]". Dessa forma, entender um discurso é "explicitar e interpretar ao mesmo tempo a relação entre as regularidades da linguagem e as significações e as finalidades ("purposes") expressas por meio [...]" desse discurso (NUNAN, 1993 apud MAINGUENEAU ; CHARAUDEAU, 2004, p. 44).

Para Orlandi (2002, p. 21-Fin22), discurso igualmente pode ser definido como sendo "efeitos de sentido entre locutores", sabendo-se que esse "[...] tem sua regularidade, tem seu funcionamento que é possível apreender se não opomos o social e o histórico, o sistema e a realização, o subjetivo ao objetivo, o processo ao produto". Também pode ser entendido, de acordo com o conceito preconizado por Maingueneau (2002, p. 43), como sendo um modo de apreensão da linguagem, esta entendida como a atividade de sujeitos inscritos em contextos determinados, para efeitos deste trabalho o organizacional.

Na visão de Ducrot (1987, p. 172), o sentido "[...] é uma representação da enunciação". Daí, poder-se falar em "efeito de sentido", que é a infinita variedade de valores de que se podem revestir os itens lexicais no discurso. Dessa forma, pode-se afirmar que os efeitos de sentido nada mais são do que o resultado dos valores atribuídos pelo discurso ao significado previamente estabelecido na língua.

Outro termo dos estudos em AD que se faz necessário na delimitação conceitual é o ethos. Para tanto, utilizará a teoria desenvolvida por Maingueneau. Esse defende que "Além da persuasão pelos argumentos [intrínsica a todo texto/comunicação], a noção de ethos permite refletir sobre o processo mais geral da adesão dos sujeitos a uma certa posição discursiva" (MAINGUENEAU, 2005, p. 69). De forma superficial, esse pode ser entendido como sendo o emissor da mensagem imbuído de características as quais foram adequadas aos receptores e que auxiliaram na conquista destes. 
Para abarcar os objetos de possíveis pesquisas com essa perspectiva, cabe trazer a noção de "cena", a qual os analistas do discurso, inspirados nas correntes pragmáticas, recorrem à metáfora teatral estóica, segundo a qual a sociedade seria um vasto teatro onde um papel seria atribuído a cada um dos atuantes (MAINGUENEAU, 1997). Pode-se, dessa forma, dizer que a língua comporta todo um arsenal de relações inter-humanas, isto é, toda uma coleção de papéis os quais o sujeito pode escolher para si próprio, apresentando-se a partir desses como enunciador(es) comunicacional(is), para se impor ao destinatário, bem como, "[...] utiliza-se, mais particularmente, a noção de 'cena' para a representação que um discurso faz de sua própria situação de enunciação" (MAINGUENEAU; CHARAUDEAU, 2004, p. 95), ou seja, a cena deve ser entendida como co-texto.

$\mathrm{Na} \mathrm{AD}$, além do conceito de "papel", tem-se ainda o de "lugar", que visa enfatizar a preeminência e preexistência da topografia social sobre os falantes que aí venham a se inscrever. A especificidade desse "[...] repousa sobre o traço essencial segundo o qual cada um alcança sua identidade a partir e no interior de um sistema de lugares [...]" (MAINGUENEAU, 1997, p. 33). Na visão de Foucault (2002), o "lugar" termina por determinar qual é a posição que pode e deve ocupar cada indivíduo para dela ser sujeito enunciativo e poder verbalizar determinadas estruturas encontradas no discurso.

Ponderado isso, igualmente se faz necessário abordar o problemática que envolve a embreagem. Esta estaria exposta nas marcas linguísticas por meio das quais se manifesta a enunciação, visto que os enunciados têm como ponto de referência o próprio ato de enunciar, do qual são produtos. Porém, só algumas características desses são levadas em consideração, aquelas que são definidoras da situação de enunciação linguística, que são: enunciadores e co-enunciadores, o momento e o lugar da enunciação. Esses três elementos formam a denominada embreagem textual à situação de enunciação, sendo apresentadas comumentes pelo "EU" e "TU" - embreagem de pessoa, marcada pela subjetividade enunciativa -, pelo "agora" - embreagem de tempo -, e pelo "aqui" - embreagem de espaço (ANDRADE, 2008, p. 72).

Passa-se agora para outra teoria que também serve de suporte para este trabalho, a Linguística
Textual (LT) que Koch (2003, p. 2-3) afirma que a maior preocupação desta

[...] é o texto, envolvendo, pois, todas as ações linguísticas [sic], cognitivas e sociais envolvidas em sua organização, produção, compreensão e funcionamento no seio social. Tais questões, contudo, só a interessam na medida em que ajudam a explicar o seu objeto de estudo - o TEXTO - e não a sociedade, a mente, a História, objetos que são de outras ciências afins.

Os textos são compreendidos por Marcuschi (2008, p. 94) como sendo

[...] uma realidade [...] Pois [...] não é apenas um sistema formal e sim uma realização linguística a que chamamos de evento comunicativo e que preenche condições não meramente formais. [...] é uma proposta de sentido e ele só se completa com a participação leitor/ouvinte. Na produção de um texto não entram apenas fenômenos estritamente linguísticos.

São exatamente esses outros fenômenos que este artigo irá se deter porque é assim que a LT auxilia a $\mathrm{AD}$ ao se debruçar nos estudos os quais versam sobre os textos e suas elaborações, bem como igualmente subsidia o trabalho dos profissionais da Comunicação Social, uma vez que esses têm como resultado final de sua atividade as produções textuais, as quais devem ser as mais conscientes, eficientes e eficazes possíveis. Para tanto, deve-se ter o maior conhecimento das teorias que detêm a atenção no estudo desse fenômeno denominado texto.

Uma das maiores contribuições da LT em suas investigações acerca dos textos centra-se justamente o estudo do estabelecimento da coerência textual. Esta, para Beaugrande (1980 apud MARCUSCHI, 2008, p. 119),

[...] subsume os procedimentos pelos quais os elementos do conhecimento são ativados, tais como a conexão conceitual. [...] representa a análise do esforço para a continuidade da experiência humana. Isto significa que [é entendida] como a continuidade baseada no sentido. [...] Na verdade, sabemos muitas coisas que não são ditas, mas que usamos na hora de interpretar um texto.

Enquanto que, para Marcuschi (2008, p. 121), "[...] é, sobretudo uma relação de sentido que se manifesta entre os enunciados, em geral [sic] de maneira global e não localizada. Na verdade, [...] 
providencia a continuidade de sentido no texto e a ligação dos próprios tópicos discursivos".

Há alguns critérios que estruturam a coerência textual, contudo para efeitos deste trabalho será destacado apenas o da intertextualidade, a qual, para Marcuschi (2008, p. 132), é “[...] mais que um critério de textualidade ${ }^{[5]}$, é também um princípio constitutivo que trata o texto como uma comunhão de discursos e não como algo isolado".

Este critério refere-se às relações que são efetuadas entre um dado texto e outros relevantes experienciados anteriormente, havendo ou não mediação para tanto (MARCUSCHI, 2008, p. 129). Marcuschi ainda adverte que "Há hoje um consenso quanto ao fato de se admitir que todos os textos comungam com outros textos, ou seja, não existem textos que não mantenham algum aspecto intertextual, pois nenhum texto se acha isolado e solitário".

Já para Maingueneau e Charaudeau (2004, p. 288), em seu Dicionário de análise do discurso,

Esse termo designa ao mesmo tempo uma propriedade constitutiva de qualquer texto e o conjunto das relações explícitas ou implícitas que um texto ou um grupo de textos determinado mantém com outros textos. Na primeira acepção, é uma variante da interdiscusividade ${ }^{[6]}$.

Barthes (1973 apud MAINGUENEAU; CHARAUDEAU, 2004, p. 289) afirma que

Todo texto é um intertexto; outros textos estão presentes nele, em níveis variáveis, sob formas mais ou menos reconhecíveis [...] O intertexto é um campo geral de fórmulas anômimas, cuja origem raramente é recuperável, de citações inconscientes ou automáticas, feitas sem aspas.

A introdutora da noção de intertextualidade, Kristeva (apud KOCH, 1991, p. 530), defende que "Qualquer texto se constroí como um mosaico de citações e é a absorção e a transformação de um outro texto".

Vale lembrar que Maingueneau (2005, p. 81) distingue "intertexto" de um discurso de "intertextualidade". O primeiro refere-se ao "[...] conjunto de fragmentos que ele cita efetivamente [...]" (citações, alusões, paráfrases etc.), ou seja, a “[...] um conjunto de textos ligados por relações intertextuais [...]" (MAINGUENEAU; CHARAUDEAU, 2004, p. 289); enquanto que o segundo "[...] é o sistema de regras implícitas que subjaz a este intertexto, o modo de citação que é julgado legítimo pela formação discusiva, o tipo ou o gênero do discurso do qual esse corpus provém" (p. 289), isto é, são "[...] os tipos de relações intertextuais que a competência discursiva define como legítimas. Todo campo discursivo define uma certa maneira de citar os discursos anteriores do mesmo campo" (MAINGUENEAU, 2005, p. 81).

Maingueneau (2005, p. 82) ainda diferencia dois tipos de intertextualidade: a interna e a externa. Aquela ocorre entre um discurso e os do mesmo campo discursivo, ou seja, é um "[...] trabalho da memória discursiva interior ao campo [...]"; enquanto que a externa acontece com os discursos de campos distintos, uma vez que "Um discurso define, além do mais, uma certa relação com outros campos, segundo citáveis ou não [...]".

A partir do exposto, advoga-se, neste trabalho, que o discurso que alerta sobre a violência urbana é construído por via de outros discursos e pela intertextualidade e é expresso nos textos produzidos pelos comunicadores sociais.

\section{TEXTOS A SEREM ANALISADOS}

Como já foi mencionado, foram selecionados três textos produzidos pelos profissionais da Comunicação Social para se empreender a análise: dois desses pertencem ao Jornalismo (charge e tirinha) e um, à Publicidade e Propaganda (anúncio publicitário).

\footnotetext{
5 Segundo Costa Val (1999, p. 5), "Chama-se textualidade ao conjunto de características que fazem com que um texto seja um texto e não apenas uma seqüência [sic] de frases".

6 "Todo discurso é atravessado pela interdiscursividade, tem a propriedade de estar em relação com outros discursos, de entrar no interdiscurso. Esse último está para o discurso como o intertexto está para o texto" (MAINGUENEAU ; CHARAUDEAU, 2004, p. 286,).
} 


\subsection{A Charge ${ }^{7}$}

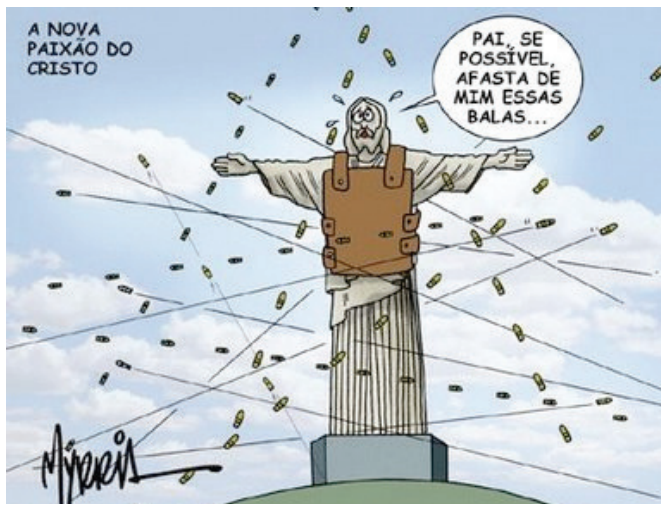

\subsection{O Anúncio Publicitário ${ }^{8}$}

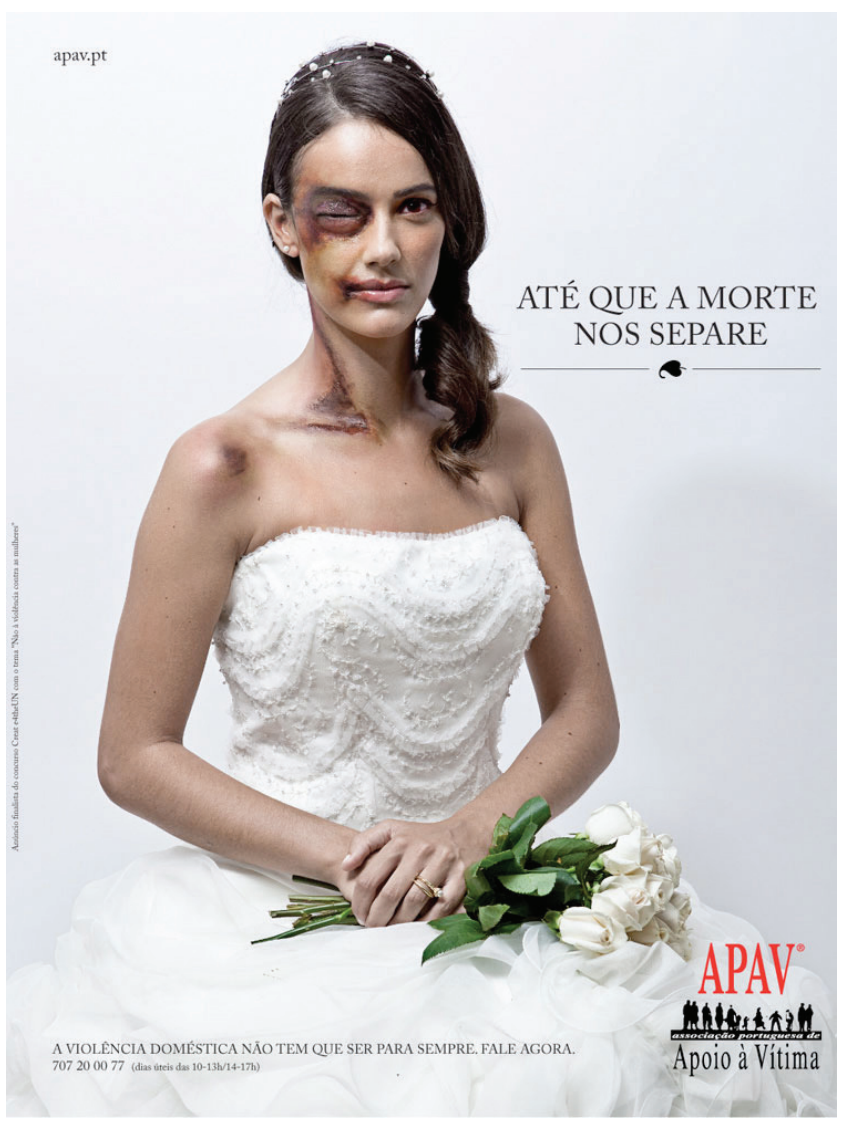

7 Disponível em: <http://conhecimentoetudo.files.wordpress.com/2009/06/ cristo20charges.jpg >. Acesso em: 22 fev. 2014.

8 Disponível em: <http://historiasdasandrafotos.blogspot.com.br/2012/11/ campanha-apav-25-novembro-dia.html>. Acesso em: 22 fev. 2014.

\subsection{A Tirinha ${ }^{9}$}

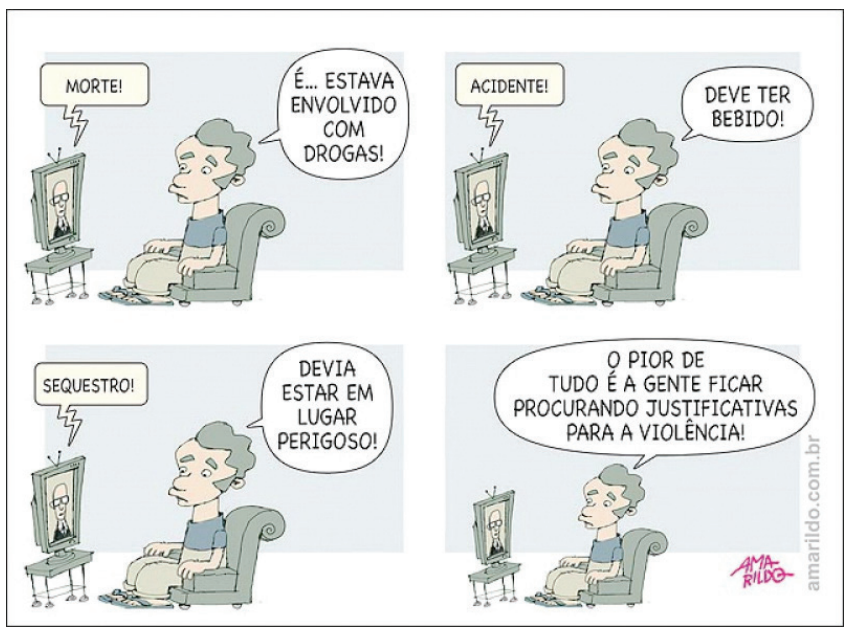

\section{ANÁLISES}

Visando realizar as análises usou-se a Análise do Discurso, de linha francesa, teoria que é igualmente uma metodologia e que facilita a realização de estudos focados nos discursos produzidos, para efeitos deste trabalho centrou-se naqueles que alertam acerca da violência urbana.

Para empreender as análises, é necessário mencionar que a violência urbana tornou-se um dos temas mais preocupantes nas sociedades contemporâneas, inclusive na brasileira, principalmente em se tratando das grandes cidades como nas capitais.

Para entender os textos produzidos pelos comunicadores sociais alertando sobre o tipo de violência estudada neste trabalho, passa-se a observar nas produções selecionadas alguns aspectos de sua construção, pois, a partir desses, pode-se apreender o discurso a ser examinado.

Na charge do item 3.1 deste estudo, observa-se que os elementos do co-texto existentes, neste texto, podem ser assim descritos: há o Cristo Redentor do Rio de Janeiro em meio a um tiroteio. Essa estátua é uma representação grandiosa de Jesus Cristo de braços abertos vendo o que acontece na "cidade maravilhosa" eo quenãofaltaneste centro sãotiroteios, bem como as várias formas de violência urbana. $\mathrm{Na}$ cena criada, o monumento toma para si esse

9 Disponível em: $<$ http://cadaminuto.com.br/blog/bispo?page=12>. Acesso em: 22 fev. 2014 
martírio, como o fez o seu representado na Bíblia. Logo aí já há a presença de um intertexto.

Este é reafirmado, igualmente, nos itens linguísticos. Existe a chamada "A nova paixão de Cristo", fazendo menção ao novo sofrimento (similar ao anterior) imposto ao Filho de Deus, ao ver a violência se proliferar desenfreadamente e tomá-la para si para salvar os seres humanos existentes na Terra. Há também a fala da estátua ("Pai, se possível, afasta de mim essas balas") que é uma clara alusão a passagem biblíca do Evangelho segundo Mateus, capítulo 26, versículo 39: ("Pai, se possível, afasta de mim esse cálice”), ou seja, aí presencia-se outro intertexto.

As intertextualidades citadas constroem um texto que claramente pertence ao discurso religioso. De acordo com Althusser (1974 apud ORLANDI, 2003, p. 241), "Deus define-se portanto [sic] a si mesmo como sujeito por excelência, aquele que é por si e para si (Sou Aquele que É) [...]”. Com isso, Orlandi (2003, p. 242-243) pode caracterizar "[...] o discurso religioso como aquele em que fala a voz de Deus: a voz do padre - ou do pregador, ou, em geral, de qualquer representante seu - é a voz de Deus". Ou seja, no texto analisado, o representante é a própria representação do Deus Filho, o que dá mais credibilidade ainda ao dito.

Observa-se que o sujeito falante (EU, quem elabora a peça, o comunicador chargista), neste texto, sofreu total apagamento em detrimento ao locutor que anuncia a cena ("A nova paixão de Cristo") e o enunciador que é um EU todo poderoso: o Deus Filho que reporta para um TU, o Deus Pai, instaurado no discuso a partir da sua fala ("Pai, se possível, afasta de mim essas balas"). O TU, para quem a peça foi pensada, fica implícito e remete-se ao pretenso leitor, mas foi instalado um co-enunciador pela fala apresentada pela estátua (Deus Filho), esse é interpelado pelo vocativo "Pai" (reportando ao Deus Todo Poderoso).

Sobre os embreantes de espaço (ou seja, as palavras ou expressões que ancoram a situação enunciativa em nível espacial), percebe-se que a presença do citado monumento situa o texto no Rio de Janeiro. Contudo, essa é apenas uma representação de outras grandes cidades que estão vivenciando o mesmo tipo de violência.

Pensando-se agora nos embreantes de tempos, aquelas palavras ou expressões que ancoram a situação enunciativa em nível temporal, esse texto possui apenas um tempo verbal o presente pontual, que é $[. .$.$] quando existe coincidência entre o \mathrm{MR}^{[10]} \mathrm{e}$ $\mathrm{ME}^{[11]}[\ldots . .] ".(F I O R I N, 2002$, p. 149). Na charge estudada, o Cristo Redentor está em meio ao tiroteio e o MR é dado pelo co-texto e o ME pelo verbo presente na fala.

Cabe destacar ainda o lugar enunciativo ocupado pelo comunicador, pois este igualmente vive em um centro urbano e também está vulnerável a encontrar-se em meio a tiros, isto é, está também vulnerável, como o Cristo, a sofrer este tipo de violência e como o Cristo, clama pelo Pai (Deus) para que acabe com esse fenômeno. Dessa forma, o ethos adquirido foi a de alguém frágil que precisa de Deus para intervir, pois os homens já perderam o controle da situação vivenciada atualmente, assim, alerta os seus pares para atentarem sobre a violência que impera nos grandes centros urbanos e até mesmo nos menores. Dessa maneira, observa-se que o discurso religioso serve como construtor de um que alerta sobre a violência presenciada nas urbes.

Passando-se agora para o estudo do anúncio publicitário (item 3.2 deste documento), observa-se que a cena criada foi a de um casamento, uma vez que o co-texto apresenta uma noiva vestida como tal. Entretanto, há um deslocamento do que se espera deste papel, que esteja linda/impecável neste dia, porém o que se vê é uma mulher espancada, ainda que apareça em indumentária para o citado ritual. Entretanto, a cena montada está em consonância com o dito "Até que a morte nos separe", ou seja, à mulher cabe a submissão dada pela voz de Deus, aceitar tudo do cônjuge, pois o que Deus uniu só a morte pode separar. Assim, mais uma vez, o discurso religioso serve para a construção de um texto que alerta acerca da violência urbana, agora com o foco na violência sofrida pelas mulheres.

Percebe-se, neste texto, como o que se presenciou na análise da charge, que o sujeito falante (o EU, quem elabora a peça, o comunicador publicitário) sofreu total apagamento em detrimento ao enunciador que é a própria noiva ("Até que a morte

10 Para Fiorin (2002, p. 145), os momentos de referência (MR) são instalados no enunciado, isto é, no decorrer do texto enquanto narrativa.

11 Segundo Fiorin (2002, p. 143), "O discurso instaura um agora, momento da enunciação", ou seja, este momento é dado em função do presente que já está implícito na enunciação/diálogo instaurado. 
nos separe"). O TU, para quem a peça foi pensada, fica implícito e remete-se ao pretenso leitor, que necessita colocar-se na posição daquela noiva retratada como sofredora de violência.

No anúncio, há um outro texto, "A violência doméstica não tem que ser para sempre. Fale agora”, em que o EU do locutor (APAV, quem promove o anúncio) aparece para interpelar um TU, aqueles que já sofreram este tipo de violência ou a testemunharam.

Cabe salientar que o "Até que a morte nos separe" instaura intertextos. Esse plural dá-se porque Deus originalmente afirma que só a morte pode separar o que Ele unir (Evangelho segundo Marcos, capítulo 10) e isso é proferido explicitamente no sacramento do matrimônio (voz do padre), isto é, primeiro intertexto; já o segundo aparece na voz da noiva remetendo a voz do vigário. Assim, este texto foi construído perpassando intensamente pela intertextualidade e sem entendê-la perderá a sua força enunciativa.

Sobre os embreantes de espaço, nota-se que apesar de espelhar no co-texto uma noiva e, portanto, remeter a um determinado casamento, este serve como representante de tantos outros em que a mulher vivencia a situação de violência. Analisando os embreantes de tempos pode-se dizer que o enunciado instaura o presente pontual, mas, ao se juntar este com o co-texto, há uma sensação de presente contínuo, "[...] quando o momento de referência é mais longo do que o momento da enunciação" (FIORIN, 2002, p. 149). Assim, salienta-se a importância do papel da imagem em um texto publicitário, a qual pode interferir diretamente na interpretação imputada no texto, alterando até, como neste caso, o sistema de interpretação do tempo da situação retratada.

Cabe destacar o lugar enunciativo ocupado pelo comunicador (o publicitário e a própria APAV), pois este constroi o discurso de alerta não como uma possível "noiva", mas como alguém que testemunha situações similares em sua cidade. Ou seja, o ethos edificado foi de alguém sensível a situação do outro e capaz de descrever algo que está presente na sociedade contemporânea. Assim, o EU do comunicador (sujeito falante) se encontra numa posição de não autoridade e deve, a partir daí, usar uma estratégia de fazer crer, que atribui ao TU uma posição de dever crer e dever indentificar-se.
Mais uma vez, nota-se que o discurso religioso é utilizado para adentrar outros discursos cujo objetivo seria impactar, sensibilizar e alertar as pessoas acerca da violência existente e vivida por milhares de mulheres.

A última produção textual a ser analisada a tirinha, presente no item 3.3 deste artigo, nota-se que nela a cena criada foi a de um telespectador assistindo a um telejornal. Os elementos do co-texto são o aparelho de televisão ligado em um telejornal (há a figura do âncora sendo projetada), posicionado em cima de uma mesinha, e o telespectador sentado em sua poltrona. Na cena criada, há papéis (emissor da notícia e o receptor dos conteúdos passados) bem delineados e conhecidos na/da sociedade contemporânea: alguém (âncora) fala para uma massa ${ }^{12}$. Isso, por si só, já determina um intertexto.

Nesta cena a presença do discurso midiático, conforme escreve Giane Serra (2001), termina por reforçar que:

[...] a legitimidade das linguagens das outras instituições e garante a sua permeabilidade por todo o tecido social. Este papel de reforço resulta da projeção pública da sua experiência, que é a de reelaborar as modalidades discursivas herméticas/fechadas em modalidades discursivas generalizantes/ abertas, confere - a elas maior visibilidade e ajuda-as a se manter [sic] presentes no imaginário social. (SERRA, 2001, s.p. ${ }^{13}$ ).

Portanto, é um discurso que reafirma o da violência, pois a mídia o noticia de forma neutra. Todavia, a tirinha em questão alerta não para esses discursos, mas para um igualmente perigoso: o que justifica o da violência urbana, presenciado nos balões indicadores da fala do telespectador.

Charaudeau (2006) parte da ideia de que, quando há a captura da realidade pela mídia, isso não acontece sem que haja um filtro particular do que se quer reter. Ou seja, realiza-se uma fragmentação do real, construindo-o a partir da seleção de acontecimentos que serão noticiados

\footnotetext{
12 Massa entendida aqui como uma quantidade substancial de pessoas distanciadas entre si ou por espaço ou por incapacidade de comunicação enquanto resposta.

13 A dissertação de Serra pode ser acessada em capítulo via Internet. Este trecho encontra-se no capítulo 2, intitulado de Discurso científico e discurso midiático e está disponível em: <http://portalteses.icict.fiocruz.br/transf. php?script=thes_chap\&id $=00002703 \& \operatorname{lng}=$ pt\&nrm=iso $>$. Acesso em: 1 mar. 2014.
} 
pelos meios de comunicação (bem como a recepção também seleciona o real que quer construir a partir do noticiado). Esses acontecimentos só se constituem/significam enquanto acontecidos quando estão num discurso. Essa seleção dos que entrarão na ordem do discurso midiático vai ser feita através de um filtro que os meios de comunicação realizam em função de dados que se relacionam com as noções de tempo, espaço e hierarquia (importância do fato).

Assim, pode-se observar que o sujeito falante (o EU, que elabora a peça, o comunicador) sofreu total apagamento em detrimento aos enunciadores (âncora e telespectador). O TU, para quem a peça foi pensada, fica implícito e remete-se ao pretenso leitor, mas instala-se um co-enunciador (telespectador). Cabe destacar, contudo, que, no último quadro da tirinha, há presença do "a gente", a qual é uma estratégia comunicativa de incorporar e responsabilizar o leitor do mesmo comportamento adotado pelo enunciador da referida fala.

Neste texto, cumpre-se o esquema da comunicação de massa, o qual é a base para o discurso das mídias, que "[...] é unilateral, ou seja, um enunciador dirige a palavra a um público relativamente indiferenciado e ausente, que não tem possibilidade de tomar efetivamente a palavra, pelo menos no decurso da sua relação discursiva" (SERRA, 2001, s.p. ${ }^{14}$ ). Essa impossibilidade parece ser um pouco contornada quando alguns dos espectadores começam a refletir e a discutir com outros acerca dos assuntos debatidos.

Sobre os embreantes de espaço, observa-se que este espelha, a partir do co-texto apresentado, um ambiente bem similar ao de muitas "salas de televisão", servindo assim como representante de tantos outros existentes em lares brasileiros, cabendo salientar a presença do intertexto na criação desta cena.

Em relação aos embreantes de tempo, apesar da presença de tempos verbais distintos ("estava envolvido" = pretérito imperfeito indicando ação contínia no passado; "deve ter bebido" = verbo "dever" está no presente (afirmação do enunciador), mas de-

\footnotetext{
14 A dissertação de Serra pode ser acessada em capítulo via Internet. Este trecho encontra-se no capítulo 2, intitulado de Discurso científico e discurso midiático e está disponível em: <http://portalteses.icict.fiocruz.br/transf. php?script=thes_chap\&id=00002703\&lng=pt\&nrm=iso $>$. Acesso em: 1 mar. 2014.
}

mais verbos apontam um passado pontual, pretérito perfeito; "devia estar" = futuro do pretérito, indicando uma suposição do enunciador), nos três primeiros quadros da tirinha, todos remetem a um MR anterior ao ME; enquanto que, no último quadro, o presente pontual que serve para chamar atenção de um comportamento pontual, neste caso, torna-se reincidente em ações individualizadas, formando um comportamento generalizado e negativo. Quando o telespectador afirma "O pior de tudo é a gente ficar procurando justificativas para a violência!", é instaurado o intertexto, pois já há outras justificativas similares às apresentadas, na tirinha, circulantes na sociedade.

Cabe destacar ainda o lugar enunciativo ocupado pelo comunicador, pois este pode possuir o mesmo comportamento alegado pelo enunciador ao declarar "a gente". Assim está incluso, em responsabilidade, de construir um discurso que "absorve" os praticantes da violência urbana noticiada nas mídias. Dessa forma, o ethos construído foi de uma pessoa que alerta outra sobre o perigo de ser assimilada pelos discursos midiáticos alienantes e circulantes na sociedade atual.

Dessa maneira, nota-se, neste texto, a presença de discursos (o das mídias, o de absolvição dos agentes da violência urbana e o de alerta sobre os anteriores) como construtores de um que alerta e funciona como interdiscurso sobre as práticas cristalizadas nos dois fundantes.

Diante das análises empreendidas, percebe-se que: a intertextualidade é o critério de constituição textual preponderante para a construção do sentido dos três textos analisados; é o intertexto que traz a força do sentido a ser edificado em cada um desses; e o discurso principal dos textos tem sua força intensificada a partir da entrada de outro em sua construção.

\section{CONSIDERAÇÕES FINAIS}

Observa-se que, ao construir um texto o comunicador social, seja este um trabalhador da impressa (chargista ou desenhista de HQs) ou um publicitário, lança mão de estratégias, como a da intertextualidade e do entrelace de discurso. Isso faz que seus textos ganhem força de sentido e se destaquem sobremaneira em meio a outros, cujas mensagens foram igualmente poderosas. 
Percebe-se, a partir das análises realizadas, que o leitor dos textos analisados também possui papel preponderante, pois tem que acionar o conhecimento dos textos que estão em posição de intertexto. Sem isso, o sentido a ser construído ficará prejudicado ou até inatingível em sua completude.

Salienta-se que objetivo deste trabalho igualmente foi atingido, pois, a partir dos estudos, conseguiu-se entender como se constroi um texto a partir do já verbalizado em outros presentes na sociedade, visando-se, assim, alertar sobre a violência urbana, bem como se explanou como outros discursos podem auxiliar na produção de um impactante, eficaz e eficiente combate a essa violência.

Cabe salientar que ainda há muito a se pesquisar sobre os discursos mencionados neste documento e quanto mais áreas lançarem luzes sobre esses (aqui entraram a teoria da Análise do Discurso, linha francesa, e a Linguística Textual) melhores serão abarcados cientificamente.

Por fim, salienta-se que neste artigo também se demonstrou que é possível estabelecer diálogos teóricos entre campos discursivos, mas é preciso que isso se torne uma constante nos bancos universitários, nas propostas de pesquisa e no trabalho diário com os textos, principalmente, os produzidos pela área de Comunicação Social, a qual é uma preponderante atividade formadora de opinião dentro da sociedade contemporânea.

\section{REFERÊNCIAS}

ANDRADE, M. C. de. Análise de textos da Comunicação Empresarial. 2008. 302 f. Tese (Doutorado em Letras) Instituto de Letras, Universidade Federal da Bahia, Salvador, 2008.

BARATA, S. de A. Violência urbana. 2008. 27 f. Artigo - Faculdade de Economia, Universidade de Coimbra, Coimbra, 2008.

CABRAL, P.; FRAZÃO, D. G. Violência urbana. Significados.com.br. Disponível em: <http://www. significados.com.br/violencia/>. Acesso em: 27 fev. 2014.

CHARAUDEAU, P. Discurso das mídias. Tradução de Angela S. M. Corrêa. São Paulo: Contexto, 2006.

COSTA, S. R. Dicionário de gêneros textuais. 2. ed. rev. ampl. Belo Horizonte: Autêntica, 2009.

COSTA VAL, M. das G. Redação e textualidade. 2. ed. São Paulo: Martins Fontes, 1999. (Coleção Texto e linguagem).
DUCROT, O. O dizer e o dito. Revisão Técnica da Tradução de Eduardo Guimarães. Campinas: Pontes, 1987.

ESTEVES, A. A criminalidade na cidade de Lisboa: uma geografia da insegurança. Lisboa: Colibri, 1999.

FIORIN, J. L. As astúcias da enunciação: as categorias de pessoa, espaço e tempo. 2. ed. São Paulo: Ática, 2002.

FOUCAULT, M. A arqueologia do saber. Trad. Felipe Baeta Neves. 6. ed. Rio de Janeiro: Forense Universitária, 2002.

GOMES, C. C. S. A face da violência urbana: questões atuais. Revista Brasil Escola (on line). Disponível em: <http:// meuartigo.brasilescola.com/atualidades/a-face-violenciaurbana-questoes-atuais.htm>. Acesso em: 27 fev. 2014.

$\mathrm{KOCH}$, I. V. Lingüística Textual: uma entrevista com Ingedore Villaça Koch. Revista Virtual de Estudos da Linguagem - ReVEL, v. 1, n. 1, ago. 2003. p. 1-4.

Intertextualidade e polifonia: um só fenômeno? Revista Delta, São Paulo, v. 7, n. 2, p. 529-543, 1991.

MAINGUENEAU, D. Gêneros do discurso. Tradução de Sírio Possenti. Curitiba: Criar, 2005.

MAINGUENEAU, D; CHARAUDEAU, P. Dicionário de análise do discurso. Coord. Trad. Fabiana Komesu. São Paulo: Contexto, 2004.

. Termos-chave da análise do discurso. Trad. Márcio Venício Barbosa e Maria Emília Amarante Torres Lima. Belo Horizonte: UFMG, 2002.

Novas tendências em análise do discurso. Trad. Freda Indursky. 3. ed. Campinas: Pontes, 1997.

Ethos, cenografia, incorporação. In: AMOSSY, Ruth (Org.). Imagens de si no discurso: a construção do ethos. São Paulo: Contexto, 2005, p. 69-92.

EVANGELHO segundo Marcos. Deus une o homem e a mulher. In: BÍBLIA Sagrada: edição pastoral. 4. impr. São Paulo: Edições Paulinas, 1990. p. 1295-1296.

MARCUSCHI, L. A. Produção textual, análise de gêneros e compreensão. São Paulo: Parábola Editorial, 2008.

ORLANDI, E. P. A linguagem e seu funcionamento: as formas do discurso. 4. ed. 3. reimpr. Campinas, SP: Pontes, 2003.

Análise do discurso: princípios e procedimentos. 4. ed. Campinas, SP: Pontes, 2002.

PHEBO, L.; MOURA, A. T. M. S. de. Violência urbana: um desafio para o pediatra. Jornal de Pediatria, Porto Alegre, v. 81, n. 5, nov. 2005. p. 189-196.

SANTOS, M. Metamorfoses do espaço habitado: fundamentos teórico e metodológico da geografia. São Paulo: Hucite, 1988. 
SERRA, G.M. A. Saúde e nutrição na adolescência: o discurso sobre dietas na Revista Capricho. 2001. $136 \mathrm{f}$. Dissertação (Mestrado em Saúde Pública) - Escola Nacional de Saúde Pública, Fundação Oswaldo Cruz, Rio de Janeiro, 2001. Disponível em: <http://portalteses.icict.fiocruz.br/ transf.php?script $=$ thes_chap\&id $=00002703 \& \operatorname{lng}=$ pt\&nrm $=\mathrm{i}$ so>. Acesso em: 1 mar. 2014.

Recebido em março de 2014.

Aceito em abril de 2014. 